\title{
A Conceptual Analysis on 'ASEAN Way' as a Normative Approach for Conducting Regional Affairs
}

\section{S.C. Padmakumara}

Department of International Relations, Faculty of Arts, University of Colombo

*Corresponding author: S.C. Padmakumara, Email: padmakumarase@gmail.com

\section{Abstract}

The role of Association of Southeast Asian Nations (ASEAN) has become more important in conducting regional affairs with its distinctive approach to interstate relations and regional cooperation. This distinctive practice is called as 'ASEAN Way' and the scholars assert that it is a pragmatic and informal approach to conduct intraregional affairs. As viewed by the scholars, what sets the ASEAN apart from many other regional institutions is its own process of decision-making, typically referred to as the "ASEAN Way' (Weber, 2019). The ASEAN Way consists of a code of conduct for inter-state behavior as well as decision- making process based on consultations and consensus among its member states (Acharya, 1997). This ASEAN model or 'ASEAN Way' provides example of how a region can manage its problem and develop a positive identity in International Relations. Therefore, both in terms of intraregional and extra regional perceptions, Southeast Asia has become a symbol of a dynamic and largely peaceful region (Acharya, 2012).

The central objective of this paper is to conceptualize the significance of 'ASEAN Way' as a distinctive approach to conduct regional affairs and highlight its implications for sustaining regional cooperation. The idea of 'ASEAN Way' is examined in this paper with specific reference to two important propositions. The first holds that 'ASEAN Way' is a normative approach to conduct intraregional affairs and it possess distinctive features compared to other regional practices. The second proposition holds that 'ASEAN Way' is potential as a mean for peaceful settlement of regional disputes. In order to realize these objectives, this study intends to answer these two research questions; what are the distinctive features of 'ASEAN Way' as an approach to conduct regional affairs and how it can be attributed as a peaceful mean for settling regional disputes. This study adopts a qualitative approach and primarily depends on the secondary data to answer the aforesaid research questions. 


\section{Introduction}

As per the scholarly perspectives, various approaches have been adopted to attribute Southeast as a region. One such approach involves a search for common attributes - physical, cultural and historical linkages and other approaches focus on the historical processes that could attribute Southeast Asia as a region (Acharya, 2012). Despite these approaches, 'ASEAN Way' clearly reflects the soft regionalism adopted by the organization, relying primarily on consultations and consensus among the members. This approach is helpful in understanding the normative culture embedded within the ASEAN institutional structures. It also helps to understand why 'ASEAN Way' should be given such prominence or why it should be considered as one of the core pillars of ASEAN normative agenda.

Although there are various models adopted for conducting regional affairs, the case of ASEAN Way is distinctive, because it demonstrates a unique and normative way of conducting regional affairs. On the other hand, this exclusive interactive culture entrenched in ASEAN has drawn substantial scholarly attention in multiple ways. According to Narine, "ASEAN has developed a method of interaction that has alleviated tensions among its member states. This method is broadly referred to as the "ASEAN way" or the "ASEAN process," and involves the use of extensive consultation and consensus building to develop intramural solidarity ( Narine,1997).According to Narine (1997),the 'ASEAN way' has implications for a larger context of regional and intra- regional affairs .As the key principles of ASEAN Way ; dialogue and consultation can successfully alleviate intra- ASEAN tensions and engender the habit of cooperation, then it should be able to produce similar effects in the larger Asia-Pacific region.

According to Acharya (1997), "ASEAN Way is not so much about the substance or structure of multilateral interactions, but a claim about the process through which such interactions are carried out" (p. 329). This perspective specifically explains that the 'ASEAN Way' involves in a distinctive process by which ASEAN members policy stances and interactions are largely shaped and reshaped. From this point of view, ASEAN Way should not be understood as a mere policy substance; instead it should be viewed as a practical approach that allow ASEAN members to constructively engage with its decision making procedures. He further explains that the ASEAN 
Way is not an unusual construct but where it can claim a certain amount of uniqueness is the manner in which these norms are operationalzed into a framework of regional interaction', (Acharya, 1997 ). This idea shows that 'ASEAN Way' is useful in explaining the normative engagement of ASEAN and, similarly it helps to understand how such norms are being transferred into the realm of its regional affairs. As Acharya (1997) point outs, this approach involves a high degree of discreetness, informality, pragmatism, expediency, consensus-building, and non-confrontational bargaining styles which are often contrasted with adversarial posturing and legalistic decision making procedures in Western multilateral negotiations. Among these features, Acharya (1997) identifies two important characteristics associated with ASEAN's approach to security cooperation. There are the preference for informality and the relative avoidance of excessive institutionalization. Perhaps, these two characteristics help ASEAN to be distinguished from the other regional settings like European Union which has been largely adhered to formal procedures and excessive institutional building processes. In addition, "the virtues of informality over structured, formalistic and legalistic procedures have been seen by decision-makers in Southeast Asia as an important feature of intra-regional relations" (Acharya, 1997). As viewed by many scholars, this 'informality' in conducting intra-regional affairs has been often reflected and highlighted by the interactions among ASEAN leaders and delegations. In fact, these practices might have created favorable space for ASEAN members to look for more accommodative and non-controversial way of conducting relations among its members. Hiro Katsumata (2003) defines the ASEAN Way in the following manner.

The 'ASEAN Way' refers to a set of diplomatic norms shared by the members of the Association of Southeast Asian Nations (ASEAN). It encourages the Southeast Asian countries to seek an informal and incremental approach to co-operation through lengthy consultation and dialogue. Its elements include the principles of non-interference in the internal affairs of other states, the non-use of force, and so on (p.104).

According to Katsumata, 'ASEAN Way' can be viewed as an assortment of diplomatic norms that urge for informal and incremental approach to achieve collaboration among ASEAN members mainly through the processes of effective consultation and dialogue. 


\section{Normative Interpretations on 'ASEAN Way'}

Normative interpretations accepts that norms matter in understanding the 'ASEAN Way'. Generally, the term 'normative' refers to associated with or conforming to norms. In addressing the question of key features of ASEAN Way, some scholars have identified the significance of the role of norms in understanding the ASEAN Way. As mentioned below, Hyung and Ping (2011) discuss why ASEAN will continue to play a significant role in the international relations of Southeast Asia while referring to constitutive norm associated with the ASEAN Way.

The reason for its significance lies in its dialogue mechanism. And such is the importance of this dialogue mechanism to ASEAN that, while dialogue is normally seen as a modus operandi, a way of doing things or a process, it has become in the ASEAN case a constitutive norm, one that is a function of the unique identities of, and relations among, the ASEAN countries (p.953).

Although, 'ASEAN Way' refers to a case of constitutive norm, there is a common consensus among the scholars that defining and measuring ASEAN norm is a challenging task, given that ASEAN is not very institutionalized and it's very informal (Hyung and Ping, 2011). This move ensures that informality and unfastened institutionalization has facilitated the "ASEAN Way" to a greater extent and serve as an incentive for cultivating unique diplomatic culture in the region. Generally, this unique diplomatic culture has been largely characterized by the norms of non-interference in the internal affairs of member states, non-use of force in the settlement of disputes, the pursuit of regional autonomy, and the practice of the ASEAN Way (Hyung and Ping, 2011). Accordingly, the 'ASEAN Way' can be considered as one of the core pillars of normative agenda in ASEAN that has significantly contributed to the unique diplomatic culture in the Southeast Asian region. Moreover, searching for the 'comfort level' of members is an important precondition for ASEAN's multilateral diplomacy, and members, for decades, have been pursuing dialogue without criticizing each other in public(Katsumata, 2003). This normative practice suggests that the outcome of avoiding public criticism could lead to compromises that are deemed essential for sustaining regional peace and cooperation. But it will not be reasonable to accept that every ASEAN member has equally assumed such conventional approach in practical politics, instead some members have distanced themselves from strict adherent 


\section{Conducting Regional Affairs}

to the ASEAN Way (Katsumata, 2003). For instance, in July 1998, Thailand proposed 'flexible engagement' policy which involves discussions of fellow members' domestic politics. Somehow, this proposal was not supported by the other members except Philippine, but it considerably contradicted with the norm of non- interference in internal affairs (Katsumata, 2003). The proponents of this argument show that, as a result of developments such as, membership expansion, emergence of non-traditional threats to security have compelled its members to deviate from the traditional 'ASEAN Way' while creating considerable asymmetry that makes for difficulty in achieving consensus (Hyung and Ping, 2011). This idea underscores the significance of security compulsions on the ASEAN Way and challenge its consistency in reaching consensus among members. However it does not mean that 'ASEAN Way' has been completely altered and its members have sought for substitute way for interacting among themselves. Therefore, it would be more reasonable to understand these changes as responses to a variety of compulsions coming from both internal and external developments associated with the organization.

In this sense, it can be argued that the 'ASEAN Way' still remains as a significant aspect of the ASEAN normative agenda and it is a deep rooted normative practice in the organization. This idea can be further supported with its two major historical affiliations. One is that, under Southeast Asian mandala system, paramount ruler has managed personal relations with the chiefs of many peripheral political centers as the paramount ruler cannot always resort to force (Katsumata, 2003). This is a good indication to say that the consensus seeking has been a long historical practice in the region and today it is reflected through what we called as 'ASEAN Way'. Secondly, 'ASEAN Way', particularly its dialogue practices, has linked with "the traditional Malay practice of mushawarah (consultation) and mufakat (consensus) (Katsumata, 2003). This continuous consultation seeking has ultimately led to a broader consensus building practice. These two instances explain that 'ASEAN Way' is not a newly emerged practice in Southeast Asia. But it has been broadly practiced in the region even during the pre-colonial time before adopting it as an institutional practice. On the other hand, it has broader connections with some of the prominent Southeast Asian traditional practices. 
As per the above discussion, it is obvious that 'ASEAN Way' should not be understood as a static idea; instead it should be viewed as a dynamic practice that has been sensitive to various socio-political developments and challenges. From scholarly point of view, this process is dynamic rather than static. 'Disagreements often exist but are not openly displayed' (Hyung and Ping, 2011, p.958). Accordingly, 'ASEAN Way' is a strategic venue with which to manage regional tension and disagreements among the member states.

\section{Significance of ASEAN Way}

As discussed in the previous sections, ASEAN Way is significant in many ways. The following diagram illustrates the significance of 'ASEAN Way' in promoting normative practices in the Southeast Asia region.

Figure 1: Multiple Interpretations on "ASEAN Way"

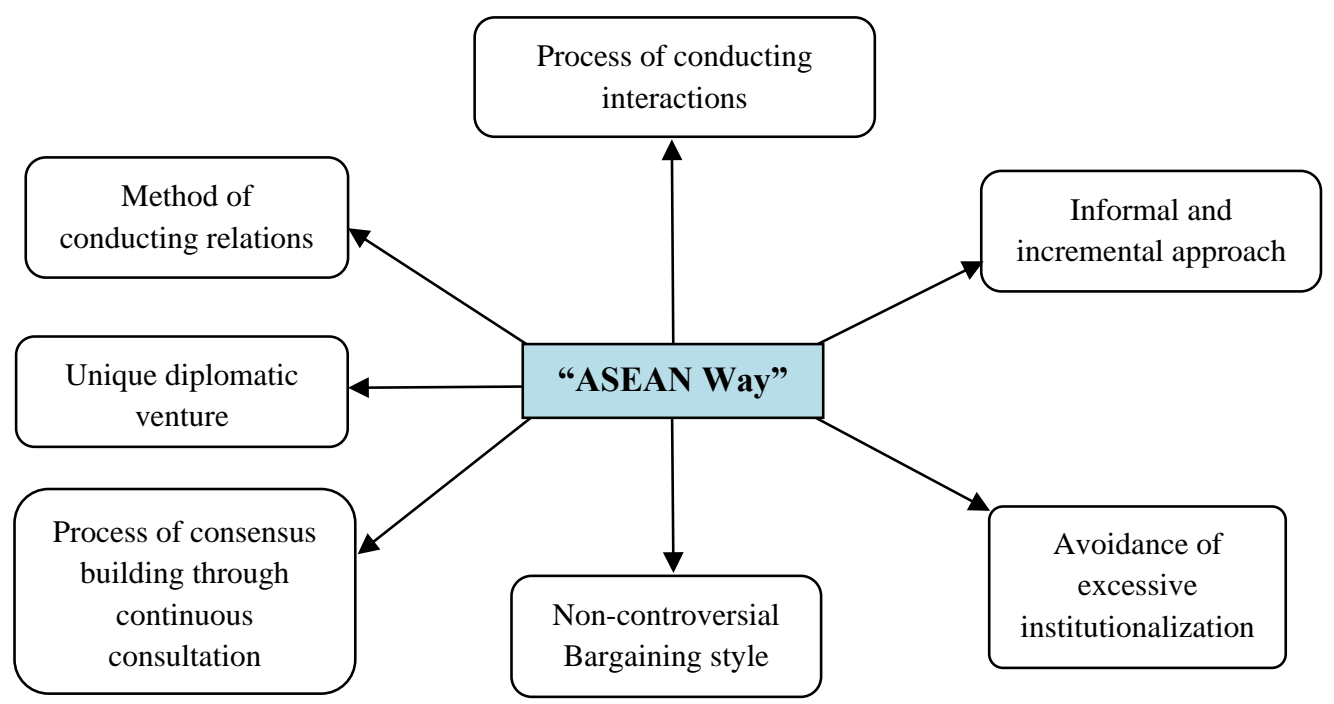

Source: Author

Given these multiple interpretations, it can be observed that the "ASEAN Way" has been differently treated by the scholars, but its core meaning as a method of conducting regional affairs lies on the practices of consultation seeking and consensus building among member states. Somehow, (Katsumata, 2003, p.106) summarizes the essence of "ASEAN Way" in the following manner; 
"Despite some minor differences in their interpretations, it is safe to say that the "ASEAN Way" has at least four elements: the principles of non-interference in the international affairs of other members, quiet diplomacy, and the non-use of force, and decision making through consensus. Some of these elements do not seem particular to Asia; however they need to be understood in the Asian context".

As pointed out by Katsumata ( 2003), some of the norms embedded in "ASEAN Way" are not exclusive to Southeast Asia, therefore, they should be carefully distinguished from the general phenomena in a relative sense by focusing on Southeast Asian context. The following table comparatively demonstrates how the practices of these norms are different in Southeast Asian context.

\section{Table 1: Why norms in 'ASEAN Way' are different? A comparison by Hiro Katsumata}

\begin{tabular}{|l|l|l|}
\hline $\begin{array}{c}\text { Norm embedded } \\
\text { in "ASEAN Way" }\end{array}$ & $\begin{array}{c}\text { General practice in the } \\
\text { other parts of the world }\end{array}$ & \multicolumn{1}{|c|}{ Southeast Asian practice } \\
\hline $\begin{array}{l}\text { Principle of non- } \\
\text { interference }\end{array}$ & Direct application & Strategic and cooperative application \\
\hline $\begin{array}{l}\text { The principle of quit } \\
\text { diplomacy }\end{array}$ & $\begin{array}{l}\text { Not a practice to a larger } \\
\text { extent }\end{array}$ & $\begin{array}{l}\text { Constructive engagement : refraining } \\
\text { public criticism and working for } \\
\text { comfort level }\end{array}$ \\
\hline Non-use of force & $\begin{array}{l}\text { Mostly associated with } \\
\text { legal means }\end{array}$ & $\begin{array}{l}\text { Through informal approach, gradual } \\
\text { promotion of a sense of mutual trust }\end{array}$ \\
\hline $\begin{array}{l}\text { Decision making } \\
\text { through consensus }\end{array}$ & $\begin{array}{l}\text { Mostly depend on majority } \\
\text { vote }\end{array}$ & $\begin{array}{l}\text { Through lengthy dialogue and } \\
\text { consultation }\end{array}$ \\
\hline
\end{tabular}

Source: Adopted from (Katsumata, 2003)

According to the above analogy, it is clear that norms embedded in 'ASEAN Way' are significantly different from the way in which they have been practiced in the other regions of the world. To elaborate from the view point of Katsumata (2003), Southeast Asia has strategically and cooperatively implemented the principle of non-interference while subduing bilateral tensions but such strategic adjustments to the same principle cannot be clearly observed in the other regions. And it is connected with the next principle of quit diplomacy which helps ASEAN members to refrain from public criticism about each other while searching for comfort level (Katsumata, 2003). 
As further shown by the comparison, the other regional settings have implemented the principle of non-use of force mostly through legal means. In contrast, in the context of Southeast Asia the same norm has been practiced in an informal way while gradually promoting a sense of mutual trust. In addition, according to Katsumata, decision making procedures in the other regional settings are often based on majority votes. However, Southeast Asian practice is different as it tends to make decisions via extensive dialogues and consultation procedures. This is certainly compatible with the Amitav Acharya's idea of 'constitute localization' which highlights the role of local agents of norms and their diffusion. As Southeast Asia has adjusted and fitted main stream norms coming from outside into its own context, it is reasonable to say that 'ASEAN Way' has largely contributed to the process of 'constitute localization' as well. In other words, 'the 'ASEAN Way' demonstrates the welding of global doctrine to 'local' conditions, in which decisions reached by consensus are indicative of the sovereign equality and hence extensive consultations, as well as comfort level, between member states (Seach, 2009). In this sense, even 'ASEAN Way' can be considered as a mean of promoting sovereign equality among the member states that could establish noncontroversial relations in the region. However, this description on 'ASEAN Way' leads to several important implications for a deep discussion on how diffusion of ideas and norms are significant in understanding the basis of ASEAN Way.

\section{Pragmatic Insights into ASEAN Way}

Drawing insights from the above discussion, this study proposes the following conceptual framework for understanding 'ASEAN Way' in order to further highlight its significance as a peaceful mean for sustaining peaceful regional affairs. In addition, it systematically illustrates how 'ASEAN Way' is operated by the member states through five suggested pragmatic stages. 
Figure 2: A Framework for Understanding 'ASEAN Way as a

Diplomatic Approach'

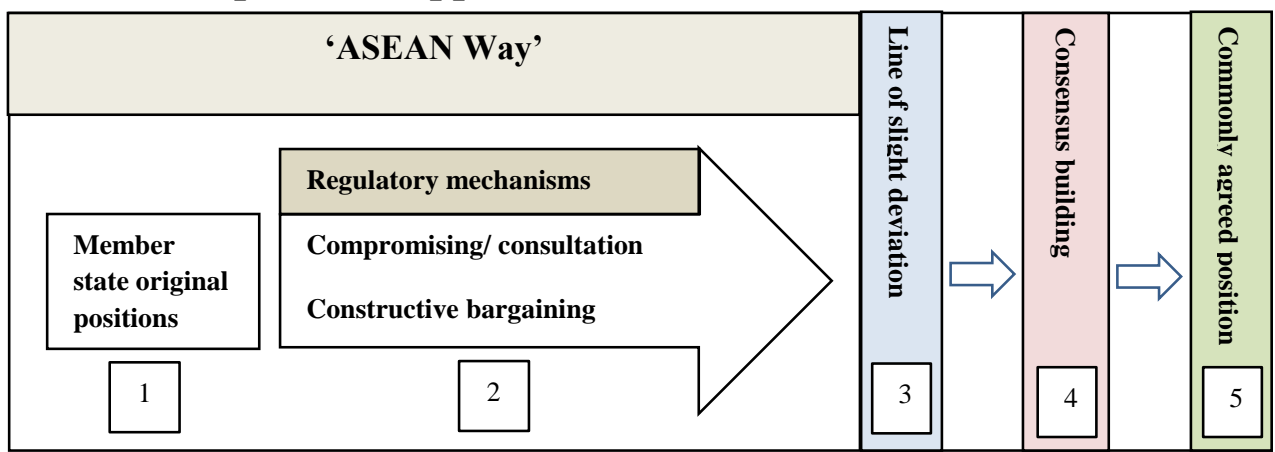

Source: Author

\section{Step 1: Instigative position}

As shown by the diagram, in the instigative position, member states hold their original positions regarding the matters concerned by the organization. Further, at this stage, they might have different policy stances, multiple perceptions, competing views and diverse understanding about the issues to be collectively concerned. Therefore in this stage, member states seek appropriate mechanism though which they can reach a certain comfort level of agreement.

\section{Step 2: Regulatory position}

When member states enter the regulatory position, their policy disparities, controversies and competing views are systematically treated through some regulatory processes such as compromising, consultation and effective bargaining. These processes ideationally transform the original standers of member states and gradually allow them to be flexible regarding the matter concerned while enabling member states to move further.

\section{Step 3: Transitional position}

After entering to the transitional position, the member states start to gradually deviate from their original positions which identified as 'line of deviation' and seek for common alternative position suggested by the organization. Thus, they start to assess the common position desired and express their willingness to do some sacrifice, adjustments required by the common position. 


\section{Step 4: Operational position}

At this stage, member states begin to practically respond to the common consensus to be reached and adjust themselves for the highest possible extent to achieve the goal. Perhaps, adjustments done by the members may be varied but at this stage members have to essentially look for a common policy diameter where all they can lie on.

\section{Step 5: Conclusive position}

The conclusive position is where all members are primed to assume a commonly agreed position and start to implement such common policy standers. At this stage, all the disparities, controversies and competing views of member states are successfully re-negotiated and members are well fitted to a common position and start to act accordingly. Hence, the conclusive position can be considered as the result of going through all four stages and the situation where 'ASEAN Way' becomes a pragmatic policy stance.

Somehow, this conceptual framework mainly aimed at illuminating the possible procedural stages of 'ASEAN Way' and presenting a systematic way in which it becomes a practical policy venture. This framework will be useful in understanding how 'ASEAN Way' is connected to a broader ideational process that could substantially transform the original policy standers of the members to a commonly agreed one. However, this framework has no way to claim that 'ASEAN Way' to be absolutely consistent with the stages suggested by the framework, thereby it is submissive to possible deviations that could be a result of nonconforming policy actions of its members or changes arise from any other atypical circumstances. In this challenging outlook, it seems that ideational engagement associated with 'ASEAN Way' can be presented as a pragmatic process than a legal framework.

\section{Extending 'ASEAN Way' beyond Southeast Asia}

'ASEAN Way' as a normative framework for conducting regional affairs can be useful in promoting regional peace and cooperation in other parts of the world. Perhaps South Asia can be one of good examples to illustrate the relevance of 'ASEAN Way' beyond Southeast Asia. The mistrust and political tension among the South Asian nations are the main obstacles for achieving peace and cooperation in the region. Therefore, this approach can provide 
needed trigger for opening dialogue among the South Asian nations to promote peace and cooperation. Ultimately, increased cooperation and peace could unlock economic growth and social benefits in the region. Likewise 'ASEAN Way' has various ramifications for other regions in the world. More specifically, the principles of consultation and consensus building embedded in 'ASEASN Way' can apply to any regional frameworks to promote regional peace and cooperation through shared understanding and collective decision making procedures among their member nations.

\section{Conclusion}

In the conclusion, 'ASEAN Way' offers a broader normative framework that ideationally integrates its member states while giving them a practice of interacting in a unique manner. However, what embedded in 'ASEAN Way' as norms are not essentially particular to Southeast Asia, but the way in which such norms are adopted and practiced by the ASEAN members has made Southeast Asian practice different from the normative practices in the other regions. Despite uncertainties surrounding political tensions between member states, 'ASEAN Way' as a normative process helps Southeast Asia to claim a common regional identity and offer 'we feeling' through a collective normative practice. On the other hand, 'ASEAN Way' establishes a certain ideational order among the member states that ultimately results a unique diplomatic behavior among the members in the region. The implementation of 'ASEAN Way' provides ASEAN members with new opportunities for sustaining multilateral relations and peace in the region. However, this approach is not exhaustive and can overcome its shortcomings while promoting goodwill and peace in the region. Finally, if the ASEAN Way is to be genuinely continued and committed to action, member nations would be able to create a more resilient environment for conducting regional affairs. At the same time, this approach has a variety of implications for other regions in sustaining regional peace and cooperation while promoting commonly agreed positions.

\section{References}

Acharya, A. (1997). Ideas, identity, and institution-building: From the 'ASEAN way' to the 'Asia-Pacific way'? The Pacific Review, 10(3), 629-652.

Acharya, A. (1999). Imagined Proximities: The Making and Unmaking of Southeast Asia as a Region. Southeast Asian Journal of Social Science, 27(1), 55-76. 
Acharya, A. (2004). How Ideas Spread: Whose Norms Matter? Norm Localization and Institutional Change in Asian Regionalism. International Organization, 58(02), 239-275.

Acharya, A. (2007). The Emerging Regional Architecture of World Politics. World Politics, 59, 629-652. http://www.asean.org/asean/asean-charter.

Ba, A. D. (2005). On norms, rule breaking, and security communities: A constructivist response. International Relations of the Asia-Pacific, 5(2), 255266. https://doi.org/10.1093/irap/lci115

Chong, A. (2012). Pre-modern Southeast Asia as a guide to international relations between peoples. Alternatives: Global, Local, Political, 37(2), 87-105. https://doi. org/10.1177/0304375412444809

Katsumata, H. (2006). Establishment of the ASEAN Regional Forum: constructing a 'talking shop' or a 'norm brewery'? The Pacific Review, 19(2), 181-198.

Rajah, A., \& Acharya, A. (1999). Introduction: Conceptualizing Southeast Asia. Southeast Asian Journal of Social Science, 27(1), 1-6.

Roberts, C. B. (2012). ASEAN regionalism: Cooperation, values and institutiona lization. Routledge.

Seah, D. (2009). ASEAN Charter. International and Comparative Law Quarterly, 58(1), 197-212.

Weber, K. (2009). ASEAN: A Prime Example of Regionalism in Southeast Asia. European Union Miami Analysis, 6(5), 1-19.

Aloysius, G. (2013). Conceptualizing the Region. New Delhi: Critical Quest.

Ruland, J. (2005). The Nature of Southeast Asian Security Challenges 36, 4. Security, 545-563.

Khoo, N. (2004). Constructing Southeast Asian Security: The Pitfalls of Imagining a Security Community and the Temptations of Orthodoxy. Cambridge, 137-153. 